\title{
HEIDEGGER E FOUCAULT, CRÍTICOS DA MODERNIDADE: HUMANISMO, TÉCNICA E BIOPOLÍTICA
}

- RESUMO: Discute-se o diagnóstico crítico da Modernidade proposto por Heidegger e Foucault enfatizando as suas continuidades. Em linhas gerais, pode-se afirmar que, em Heidegger, é a reflexão filosófica que se assume enquanto essencialmente histórica, ao passo que, para Foucault, é a investigação essencialmente histórica que assume o caráter de reflexão filosófica. No entanto, ainda que a partir de démarches teóricas distintas, ambos consideram que a compreensão a respeito de quem somos, hoje, depende de uma análise da constituição da modernidade como época histórica determinada pelo humanismo, isto é, pela concepção do homem como senhor da totalidade do ente (Heidegger) e pela concepção do homem como sujeito e objeto de relações de poder-saber (Foucault). Tal mutação epocal na concepção do humano foi decisiva para a liberação da revolução científica que culminou na técnica moderna e na biopolítica. Se, como afirma Foucault, a biopolítica é a política de nosso tempo, ou seja, de uma época que politizou o fenômeno da vida por meio de sua gestão técnico-administrativa, então a técnica moderna, que implica a concepção do homem como sujeito assujeitado pela tecnologia, constitui a instância por meio da qual a vida humana pode ser simultaneamente produzida e aniquilada por meios científicos.

- PALAVRAS-CHAVE: Foucault; Heidegger; modernidade; humanismo; técnica moderna; biopolítica.

O presente texto centra-se na discussão do diagnóstico crítico da Modernidade proposto por Heidegger e Foucault, os quais apresentam peculi-

1 Professor Adjunto do Departamento de Filosofia e do Programa de Pós-Graduação em Filosofia da Universidade Federal do Paraná-UFPR. Artigo recebido em set/06 e aprovado para publicação em out/06. 
aridades e diferenças inegáveis, visto que ambos elaboraram suas reflexões a partir de procedimentos teóricos distintos, visando objetivos também distintos, bastando, para confirmá-lo, abrir qualquer um de seus livros e compará-los. Não se trata, portanto, de abolir as diferenças que afastam ambos pensadores, as quais, evidentemente, determinam a especificidade de suas reflexões sobre a modernidade, mas de estabelecer entre eles uma delicada relação de continuidade em meio à diferença, de tal modo que possamos iluminar o pensamento de Foucault pelo de Heidegger e o de Heidegger pelo de Foucault. Tal projeto de esclarecimento mútuo encontra sua motivação em uma das últimas declarações de Foucault, em que ele afirma, de maneira algo surpreendente e enigmática, que "Heidegger sempre foi para mim o filósofo essencial. (...) Todo meu futuro filosófico foi determinado por minha leitura de Heidegger" (Foucault, 1994a, p.703). Confrontar as reflexões de Foucault e de Heidegger sobre a modernidade nos ajuda a compreender não apenas o que unifica e, ao mesmo tempo, especifica o pensamento de ambos, isto é, a tarefa de empreender um diagnóstico do presente, para o quê ambos elaboraram um diagnóstico crítico da modernidade.

Segundo a chave interpretativa aqui proposta, que busca delinear a unidade em meio à diferença, penso que as reflexões de Foucault sobre o humanismo e o biopoder poderiam mostrar-se como a contrapartida histórica, ôntica, das análises historiais-ontológicas de Heidegger, reforçandolhes sua dimensão de facticidade. As análises arqueológicas de Foucault sobre as condições epistêmicas nas quais o homem tornou-se sujeito e objeto do conhecimento; bem como suas investigações genealógicas sobre o caráter positivo do poder, isto é, sobre sua capacidade de constituir a realidade e o próprio homem no contexto micro-político das instituições modernas, podem iluminar a radicalidade historial da crítica ontológica de Heidegger à modernidade tecnológica. Se for possível demonstrar que há uma relação de complementaridade entre as análises históricas de Foucault e a crítica historial-ontológica promovida por Heidegger, então será possível contestar a avaliação crítica, a meu ver errônea, de que o filósofo alemão teria deformado sua compreensão da modernidade pelo procedimento da "abstração via essencialização", como formulado por Habermas (Habermas, 1989). Para este autor, a história do ser de Heidegger se "desconecta dos eventos políticos e históricos" e assume o caráter fantástico e fatalista de uma "história da metafísica resolutamente estilizada", construída a partir da "abstração dos contextos da vida social" e, portanto, desprovida de qualquer filtragem pelo conhecimento das ciências sociais: "Quanto mais a história real desapareceu por detrás da 'historicidade' heideggeriana, tanto mais fácil foi para Heidegger adotar um apelo ingênuo, embora pretensioso, a um 'diagnóstico do presente' assumido ad hoc" (Habermas, 1989, p.434). 
Por sua vez, a crítica ontológica de Heidegger à modernidade como época do acabamento da metafísica, manifesto e levado a cabo no desvelamento tecnológico do ente na totalidade, nos ajuda a compreender que a reflexão arqueo-genealógica de Foucault não considera a história apenas à luz da análise historiográfica dos acontecimentos factuais, visto que o seu significado e implicações históricos demandam uma interrogação filosófica do presente. Por certo, Foucault não pensa a história como um conjunto de acontecimentos dotados de sentido ou telos a priori e, portanto, como passível de totalização a partir de um fundamento ontológico determinado, seja ele a subjetividade, a consciência constituinte ou qualquer outro. No mesmo sentido, ele também critica e rejeita veementemente o que chamou de história feita por filósofos para filósofos, enfatizando a descontinuidade e o acaso que permeiam o surgimento de práticas e discursos humanos cuja compreensão exige a pesquisa historiográfica minuciosa (Foucault, 1982, p.15). Para Foucault, era preciso superar a obsessão filosófica que considera como 'histórica' apenas a questão da sucessão dos eventos, descentrando a investigação historiográfica da busca da causalidade que move a história.

No entanto, tais ressalvas não significam que a pesquisa histórica foucaultiana se oriente e se esgote no trabalho da interpretação desinteressada das fontes primárias, nem tampouco implicam que o autor se recuse a estabelecer generalizações teóricas, de caráter propriamente filosófico, capazes de capturar as principais determinações e orientações à luz das quais os discursos e práticas de uma determinada época histórica tornam-se significativos. Para dar apenas um exemplo: "As 'Luzes' que descobriram as liberdades inventaram também as disciplinas" (Foucault, 1984b, p.195). Discordo, pois, da perspectiva assumida por Rabinow, segundo a qual a genealogia de Foucault se distinguiria da perspectiva epocal de Heidegger, visto não pensar a modernidade sob a categoria temporal generalizante da 'época', mas sim em termos de um 'ethos' moderno, descoberto por Kant e, portanto, marcado pela atitude crítica moderna, totalmente distinta da atitude teórica "contra-moderna" de Heidegger. A despeito de reconhecer que "há algumas passagens nas quais Foucault pode ser lido de maneira legítima como epocal", especialmente quando profere "argumentos gerais a respeito de tendências de longa-duração", como a "sociedade carcerária", Rabinow insiste em que "o vínculo estabelecido por Foucault entre a dimensão genealógica e tais argumentos que soam epocais (epochal-sounding claims) é retórico, visando exagerar um grupo de práticas de maneira a despertar a vigilância da audiência" (Rabinow, 1994, p.203). Penso que tal afirmação desconsidera os ganhos teóricos obtidos pelas reflexões 'epocais' de Foucault em Vigiar e Punir e Em defesa da sociedade, nas quais se encontra uma avaliação crítica da modernidade como época, em nome de um texto como "Nietzsche, a genealogia e a história", o qual, a despeito de 
sua relevância, não deveria ser tomado como um estrito cânon metodológico do trabalho que o genealogista Foucault viria a empreender posteriormente. Ademais, a reflexão epocal não se confunde com a recusada busca da origem essencial e trans-histórica, visto que trata de demarcar descontinuidades em relação a épocas passadas. Se Foucault não enxerga a história à luz de um fundamento ontológico, ele também não deixa de observar as mutações que demarcam épocas, no interior das quais se observam homogeneidades e continuidades discursivas e extra-discursivas de longa duração, à luz das quais o filósofo nos oferece o diagrama de uma época determinada. Isto significa que o caráter genealógico de suas pesquisas, as quais requerem uma pesquisa historiográfica meticulosa, detalhada e restrita, se fazem acompanhar por todo um conjunto de argumentos generalizantes, propriamente epocais, por meio dos quais Foucault pensa os efeitos globais das práticas e discursos descobertos topicamente. Contrariamente a Michael Donnelly, que, ao menos reconhece a existência de argumentos genealógicos e epocais na reflexão de Foucault, não penso que tais procedimentos se caracterizem por uma "irredutível diferença" (Donnelly, 1999, p.197), mas, antes, por uma saudável complementaridade. Como afirmou Martins, "Se Foucault verga seu pensamento como um arco em direção ao passado, é para transpassá-lo e ferir com suas setas o presente" (Martins, 2000, p.151). Neste sentido, pensar a história de maneira genealógica não se restringe à descoberta e descrição historicamente delimitada e conjuntural de um conjunto de práticas e discursos oriundos de motivações heterogêneas, desprovidas de uma unidade capaz de ser explicada causalmente, mas significa pensar o presente no contraponto do passado, isto é, pensar aquilo que ainda somos e aquilo que já estamos deixando de ser.

O que a filosofia de Heidegger nos ajuda a compreender quando nos aproximamos das pesquisas históricas de Foucault é o fato de que tal reflexão não se reduz ao trabalho do historiador tradicional, mas se constitui enquanto "exercício filosófico" que busca "saber em que medida o trabalho de pensar a própria história pode liberar o pensamento daquilo que ele pensa silenciosamente, e permitir-lhe pensar diferentemente" (Foucault, 1984a, p.14). Ou seja, a reflexão foucaultiana deve ser caracterizada como uma reflexão filosófica 'sobre' e 'a partir' da história, por meio da qual Foucault procurou compreender os "jogos entre o verdadeiro e o falso, através dos quais o ser se constitui historicamente como experiência, isto é, como podendo e devendo ser pensado" (Foucault, 1984a, p.12). Ou, para retomar uma outra formulação de Foucault a respeito da complicada relação entre história e filosofia ao longo de sua obra: "Meus livros não são tratados de filosofia nem estudos históricos; no máximo, são fragmentos filosóficos em canteiros históricos" (Foucault, 1994b, p.21). Para Foucault, os acontecimentos históricos não podem ser explicados pelo simples recurso à noção de práxis huma- 
na, visto que, na época moderna, toda práxis e todo discurso são já o efeito de relações estruturadas por epistemes e dispositivos de saber-poder que os possibilitam. Por isto, a investigação histórica de Foucault, tanto na fase arqueológica quanto na fase genealógica, prescinde da categoria da causalidade e da categoria do sujeito como instância soberana e unificadora da totalidade histórica. Ao longo de toda sua reflexão, Foucault duvida da existência de um domínio positivo como 'a' história, compreensível a partir da investigação da práxis ou da consciência humana como seu motor. Em outras palavras, a inteligibilidade dos acontecimentos e documentos históricos depende da consideração de mutações, transformações e rupturas que, manifestas no plano dos acontecimentos documentados, não são redutíveis a eles, pois não podem ser explicados causalmente por eles. Em termos heideggerianos, diríamos que todo comportamento humano se dá numa clareira do ser, num espaço aberto e já significado lingüisticamente, instância pela qual o homem que age e fala historicamente não é o responsável, e que se transforma demarcando épocas distintas entre si.

\section{O diagnóstico heideggeriano da modernidade}

A concepção heideggeriana a respeito das relações fundamentais entre modernidade, técnica e ciência encontra suas primeiras formulações mais precisas no ensaio "A época da imagem do mundo", de 1938 (Heidegger, 1994a). Nele, Heidegger pensa a modernidade como uma época determinada por um novo projeto metafísico fundamental, isto é, por uma nova interpretação do ente na totalidade e por uma nova apreensão da verdade. O fundamento metafísico que concede a cada época a sua "forma essencial" possibilita os principais fenômenos que distinguem essa época. Se na modernidade predominam a moderna ciência natural matematizada e a técnica mecanizada, entre outros fenômenos, então a compreensão destes fenômenos exige compreender o próprio fundamento metafísico que os possibilitou: "Se se conseguir chegar ao fundamento metafísico que funda a ciência enquanto ciência moderna, então a essência da modernidade tem de se deixar reconhecer em geral a partir dele" (Heidegger, 1994a, p.75). Sua reflexão se inicia com a análise da descontinuidade instaurada entre a ciência moderna, a scientia da Idade Média e a episteme da Antigüidade, levando à conclusão de que a ciência moderna tem de ser pensada enquanto investigação que procede de maneira metódica e rigorosa segundo experiências pré-orientadas por leis, levadas a cabo por cientistas que operam de maneira técnica e especializada em empresas institucionalizadas. A partir daí, Heidegger então formula sua tese a respeito do fundamento metafísico que perpassa a ciência moderna e todos os fenômenos decisivos da 
modernidade: para os modernos, o ser dos entes reside em seu caráter de objeto representado por um sujeito, ao mesmo tempo em que a essência da verdade passa a ser definida como certeza da representação. Para os modernos, pensar é re-presentar (Vor-stellen), isto é, capturar e trazer o ser do ente para diante do sujeito que conhece, objetivando-o, de modo a que possa ser conhecido com certeza e permaneça sempre disponível para seu emprego calculado. Em outras palavras, o conhecimento proporcionado pela ciência moderna enquanto investigação é sempre um ajuste de contas, um contabilizar calculado a respeito da possibilidade do ente tornar-se disponível para a representação. Por sua vez, o ente só se torna disponível para a representação antecipada, calculadamente certa e exata, na medida em que se transforma em objeto de uma representação: "O ente na totalidade é entendido de tal maneira que ele somente é na medida em que é posto pelo homem que representa e produz. Ali onde chega a dar-se algo como uma imagem do mundo, perfaz-se uma decisão essencial sobre o ente na totalidade. Busca-se e encontra-se o ser do ente na representabilidade do ente" (Heidegger, 1994 a, pp.89-90).

O fundamento metafísico de tal conhecimento certo se encontra formulado no postulado cartesiano do ego cogito, sum, vale dizer, na concepção subjetivista do homem como subjectum, como o fundamento absoluto e inquestionável da verdade, e, portanto, como aquilo que pre-jaz (Vor-Liegende) e reúne tudo sobre si enquanto seu fundamento. O que se passa aqui, pensa Heidegger, é uma transformação na essência do homem, a partir da qual ele passa a ser concebido como sujeito que tem diante de si objetos, para os quais deve buscar um conhecimento objetivo, estatuto que teria sido impensável para o homem antigo ou medieval. Subjectum é a tradução latina de hipokeímenon, aquilo que subjaz, o subjacente que reúne tudo previamente sobre si, e Heidegger observa que, antes da modernidade, subjectum e hipokeímenon não estavam vinculados ao homem ou ao eu. A partir da modernidade, entretanto, o homem como subjectum torna-se o centro de referência da totalidade do ente, a instância ontológica fundante na qual o ente na sua totalidade se vê reunido e fundado. Com essa mutação ontológica, afirma Heidegger, Descartes "cria ... o pressuposto metafísico para a antropologia futura", assunto ao qual retornaremos adiante (Heidegger 1994a, p.99). Enquanto tal, essa mutação requer uma transformação na concepção do próprio ser, isto é, sua transformação em imagem, motivo pelo qual apenas na modernidade surgem visões ou concepções de mundo. Imagem de mundo (Weltbild) significa que tudo o que 'é' - natureza, mundo, história, cosmos -, apenas o 'é' na medida em que se transformou em imagem conceitualizada, em representação intelectual que objetifica o ente a partir da referência fundamental à subjetividade. O mundo como imagem é o ente na sua totalidade enquanto objeto para o conhecimento sistemático 
de um sujeito. Isto tem duas conseqüências principais. Em primeiro lugar, na modernidade a verdade nunca é pensada como o próprio desvelamento (alétheia/Unverborgenheit) do que se apresenta em sua presentidade (Anwesenheit), mas apenas como correspondência assegurada, isto é, certa, calculada e indubitável entre aquilo que 'é' e as representações do sujeito. Em segundo lugar, ao homem definido essencialmente enquanto subjectum pertence a decisão metafísica quanto à objetificação de tudo o que é, motivo pelo qual o homem se torna o único centro e o único metro a partir do qual os entes podem ser o que são. Daí decorre o humanismo constitutivo do projeto metafísico dos modernos, em que a própria essência humana se transforma. Quando Heidegger define a modernidade como a "época da imagem do mundo", portanto, o que ele pretende é caracterizar essencialmente a época em que tudo o que "é' adquire o "selo do Ser" por meio da representação do subjectum, que projeta o ser dos entes enquanto objeto e assim se assegura da sua disponibilidade calculada e previsível.

Com a revolução cartesiana, que transforma o mundo em imagem representada por um sujeito, lançam-se as condições para a posterior identificação entre subjetividade e humanidade, revelando-se, então, o sentido metafísico de termos como humanismo e antropologia, ou seja, "a interpretação filosófica do homem que explica e valora o ente em sua totalidade a partir do homem e para o homem" (Heidegger 1994a, p.86). Veremos, adiante, que a concepção foucaultiana do humanismo é distinta, posto que não encontra em Descartes sua gênese, e posto que o autor a pensa em termos da transformação do homem em sujeito e objeto do conhecimento empírico. De qualquer modo, o centro gravitacional da avaliação crítica de Foucault e de Heidegger a respeito da modernidade é o humanismo, ainda quando entendido distintamente.

Exatamente aí onde nossa consciência moderna vislumbra um movimento reflexivo de desalienação e emancipação do homem, Heidegger detecta a constituição de um efeito colateral perverso. Foi apenas a partir do momento em que o homem, enquanto subjetividade, tornou-se o senhor da totalidade dos entes, que se libertaram definitivamente as forças técnicocientíficas por meio das quais o homem moderno se tornou capaz do máximo controle, da máxima produção e da máxima destruição planificada dos entes, ele mesmo, gradativamente, incluindo-se neste processo fáustico. Já em 1935, Heidegger esboçara tais pensamentos em sua análise do fenômeno moderno da despotenciação do espírito (Entmachtung des Geistes), isto é, da conversão do espanto diante do mistério do ser em cálculo metódico e inteligente, capaz de assegurar a plena posse e domínio da totalidade dos entes, tornando-os disponíveis para sua manipulação, distribuição em massa e para a sua própria organização planejada. Ao discutir o problema da moderna ruptura da relação essencial entre homem e ser, pensada em ter- 
mos da transformação e degeneração do espírito em inteligência, a qual, por sua vez, permite a conversão do espírito em instrumento, Heidegger afirma que este, assim instrumentalizado, pode então ser dominado, ensinado e passado adiante, destinando-se à "regulação e dominação das relações materiais de produção (como no marxismo), ou, em geral, servindo à ordem inteligível e à explicação de tudo o que está dado e posto em cada caso (como no positivismo), ou realizando-se na organização e orientação da massa vital e da raça de um povo" (Heidegger, 1998, p.36). A menção ao positivismo (EUA), ao marxismo (URSS) e à condução da massa vital da raça de um povo (Alemanha nazista) deixa entrever que, já em 1935, o filósofo compreendera que os três principais pólos de poder de seu tempo conjugavam em uníssono a mensagem da organização técnica e planificada de tudo, garantida pelo pressuposto metafísico, humanista, que elevou o homem, enquanto subjectum, ao epicentro da totalidade dos entes. Quando o contrário do espírito se converte na única realidade instaura-se um mundo plano, planificado e incapaz de reflexão, caracterizado por Heidegger por meio da metáfora do espelho oxidado que não reflete mais nada. Ao pensar os acontecimentos históricos do presente em sua essência, isto é, em seu caráter metafísico-historial, como novo projeto de desvelamento do ser, Heidegger parece ter descoberto o motivo pelo qual a ciência e a técnica predominam na modernidade: é que apenas agora o homem se entrega absolutamente ao controle calculado dos entes, sem jamais se abrir em pensamento para o ser. Por sua vez, a partir do momento em que o homem, enquanto sujeito, se assume como fundamento do ente na totalidade, a relação entre sujeito e objeto se expande e assume diversas possibilidades complementares, variando de gradação entre o eu individual e o nós comunitário, visto que, em cada caso, sempre se restaura e se amplifica uma relação de dominação calculada e violenta, de asseguramento contínuo e planejado de todos os entes, levado a cabo pela ciência e pela técnica modernas:

O homem, entendido no Iluminismo como ser racional, não é menos sujeito que o homem que se compreende como nação, que se quer como povo, que se cria como raça e que finalmente se outorga a si mesmo poder para converter-se em dono e senhor do planeta. (...) No imperialismo planetário do homem tecnicamente organizado, o subjetivismo do homem alcança seu mais alto cume, a partir do qual ele descerá e se instalará no plano da uniformidade organizada. Esta uniformidade passa a ser o instrumento mais seguro para o total domínio técnico da terra. A liberdade moderna da subjetividade é completamente absorvida na objetividade que lhe é conforme. (Heidegger, 1994a, p.111)

Foi a descoberta deste fundamento metafísico que permitiu a Heidegger desfazer a aparente distinção entre as figuras modernas do homem como indivíduo, como nação, como povo ou como raça, e ainda, como ente 
racional e como animal vivo que labora (Heidegger, 1994b, p.62). Em cada um dos casos, um mesmo fundamento revela a face violenta, uniformizada e animalizada - por que não dizê-lo, biopolítica - deste ente que, ao espelhar sua dignidade em suas conquistas técnico-científicas, afunda-se cada vez mais no esquecimento do ser que o impele a seguir freneticamente sempre adiante, num movimento de criação e destruição da vida em nome da vida humana. Compreende-se, portanto, como também o fez Michel Foucault, que é exatamente no momento em que a política assume para si o cuidado e a gestão da vida que o massacre das vidas humanas mais se intensifica, pois o sujeito que pretende assumir o controle dos processos de produção técnica do real é também o objeto consumido e aniquilado em massa. Para Heidegger, como para Foucault, não será por outro motivo que os genocídios se tornaram rotina no mundo contemporâneo.

Se, como pensa Heidegger, a metafísica iniciou seu período de consumação com a elevação cartesiana do homem à estatura ontológica da subjetividade, será com Nietzsche que a metafísica entrará em sua fase de pleno acabamento, movida pelo voluntarismo expansivo de uma vontade de poder que pretende submeter a tudo, abolindo, inclusive, a distinção entre sujeito e objeto, implicada na concepção do ser humano como "fundo de reserva" (Bestand). Em meio ao mais extremo esquecimento do ser, manifesto no predomínio inconteste dos entes e na total perda de sentido da questão pelo ser, o homem do final da metafísica abandona a verdade como des-velamento originário do ser e se apega tão somente a si mesmo e à caça dos demais entes, querendo tão somente a si mesmo como o voluntário e o funcionário da vontade que a tudo pretende controlar, calcular e ordenar. A partir dessas concepções, Heidegger pensa os conflitos entre os povos na modernidade como conflitos inerentes à vontade de querer, que mobiliza os agenciamentos da técnica moderna. É porque a vontade de vontade tornouse o fundamento subjacente às atividades e comportamentos do presente que, na modernidade, o poder se tornou o elemento determinante, pensado como poder de dominação incondicional que perpassa e constitui todas as relações sociais. O homem moderno, metafisicamente pensado, é o homem que tem de servir a algum propósito, isto é, o homem que não pode deixar de servir e que, ao perder sua serventia, pode ser descartado. Nesse contexto, empalidecem também as distinções entre guerra e paz, entre os domínios nacional e internacional, pois o que persiste é um mesmo processo de transformação do mundo em um "não-mundo" (Unwelt), no qual a funcionalidade e a operacionalidade incondicionais não deixam margem para qualquer mistério. A despeito da biopolítica não se encontrar formulada no pensamento de Heidegger, ela se encontra, ao menos, pensada em suas determinações fundamentais: é no mundo da técnica planetária que o homem se transforma em matéria-prima e em agenciador de matéria-prima e 
de recursos humanos, representando-se, simultaneamente, como super-homem e como sub-homem, como razão e como instinto, visto que o instinto é agora a figura do intelecto capaz de calcular, ordenar, organizar, representar e dominar incondicionalmente, garantindo-se, assim, a produção e a destruição do próprio homem:

Como o homem é a matéria-prima mais importante, pode-se contar que, em virtude da pesquisa química contemporânea, algum dia fábricas haverão de ser construídas para a produção artificial de material humano. (...) O crescimento do número de massas humanas é impulsionado intencionalmente por meio de planificações, para que nunca falte ocasião de reclamar maiores 'espaços vitais' para as grandes massas, espaços que, por sua magnitude, exigirão para sua instalação massas humanas que serão, conseqüentemente, maiores. (Heidegger, 1994b, pp.89-93)

Penso que a figura heideggeriana do homem considerado como ser vivo cuja existência depende do investimento tecnicamente planejado para a produção de novos seres vivos, destinados a cumprir o papel de uma uniformização do mundo, tem sua contrapartida complementar nas análises foucaultianas que mostram como foi que o homem moderno tornou-se o foco do agenciamento de poderes e saberes que o constituíram como sujeito assujeitado.

\section{O diagnóstico foucaultiano da modernidade}

Em suas pesquisas arqueológicas, Foucault investigou as configurações e deslocamentos epistêmicos que estabelecem os limites entre o que é pensável e o que é impensável, entre o que é dizível e o que é indizível no âmbito histórico do conhecimento. Para Foucault, a episteme não é sinônimo de saber, é uma ordem ou princípio de ordenação histórica dos saberes anterior a qualquer enunciação visando o conhecimento e que a torna possível: trata-se da instância subterrânea que permite uma certa configuração do saber em uma determinada época, isto é, trata-se do solo fundamental que confere legitimidade e positividade ao saber histórico. Em outras palavras, Foucault não faz uma história das ciências nem uma história das idéias, mas descreve a configuração e as transformações históricas das diferentes epistemes, o que, por isso mesmo, não o torna um epistemólogo. Epistemes diferentes marcam diferentes possibilidades de pensamento e conhecimento ao longo da história, sem que haja uma linearidade progressiva na passagem de uma episteme a outra. Se as epistemes definem as condições de possibilidade (não universais, mas históricas) de todo saber em cada época histórica determinada, haverá apenas uma episteme regendo os discursos que visam o conhecimento naquela época. 
Em As Palavras e as Coisas, de 1966, Foucault define a episteme como o "solo" ou o "espaço comum" a partir e em função do qual os saberes de uma dada época histórica tornaram-se possíveis e enunciáveis. Ao referirse à "enciclopédia chinesa" descrita por Borges, Foucault chama a atenção não para o caráter relativo de toda forma de ordenação e classificação do conhecimento, mas para o fato da existência "bruta" ou "muda" da própria "ordem" como condição de possibilidade do conhecimento. Subjacente a toda cultura e, portanto, a toda forma de conhecimento, Foucault detecta a existência de uma ordem, de um "espaço de identidades, de similitudes, de analogias", segundo o qual classificamos e distribuímos os objetos do conhecimento: "não há, mesmo para a mais ingênua experiência, nenhuma similitude, nenhuma distinção que não resulte de uma operação precisa e da aplicação de um 'critério prévio'" (Foucault, 1995, p.9). Esta ordem não se deixa perceber enquanto tal no nível da superfície, isto é, no plano dos nossos discursos, dos nossos pensamentos e das nossas práticas cotidianas; por outro lado, é já em função desta ordem, que se esconde nas profundezas, que nós falamos o que falamos, fazemos o que fazemos, pensamos o que pensamos. O objetivo de Foucault àquela época era realizar uma investigação arqueológica visando compreender quais são as identidades, as homologias, isto é, qual é o espaço comum subjacente às diferentes ordenações dos diversos saberes de uma determinada época histórica, ou seja, qual é o espaço comum em função do qual se tornam possíveis os diferentes critérios de produção e avaliação dos conhecimentos em cada época histórica.

A despeito de todas as diferenças, parece haver uma similaridade entre essas considerações de Foucault a respeito do modo de ser da ordem, à luz do qual um determinado conjunto de proposições se torna inteligível e enunciável, e a reflexão heideggeriana a respeito do ser como a abertura historial na qual o homem histórico se encontra, caminho teórico por meio do qual Heidegger procurou determinar o fundamento metafísico de cada época particular. À primeira vista, a episteme foucaultiana não parece operar como um fundamento epocal que torna possível os principais fenômenos que distinguem uma época, à maneira Heidegger, visto que Foucault a restringe ao campo do saber. No entanto, em inúmeras passagens de As palavras e as coisas, e sobretudo de textos que se encontram ao seu redor, Foucault vai além daquela restrição e chega mesmo a afirmar que o modo como nos vemos e nos concebemos, o modo como interpretamos o que é o mundo e como nos situamos nele, definindo nossas tarefas, depende das e está fundado nas articulações de uma dada episteme, ou daquilo que, sob a inspiração estruturalista do momento, ele denominou como 'sistema', em uma entrevista de maio de 1966:

Em todas as épocas, a maneira como as pessoas refletem, escrevem, julgam, falam (até as conversas na rua e os escritos mais cotidianos), e mesmo a maneira 
como as pessoas experimentam as coisas, como a sua sensibilidade reage, todo seu comportamento é dirigido por uma estrutura teórica, um sistema que muda com as épocas e as sociedades - mas que é presente a todas as épocas e a todas as sociedades. (...) Pensa-se no interior de um pensamento anônimo e constringente que é o de uma época e de uma linguagem. Este pensamento e esta linguagem têm as suas leis de transformação. A tarefa da filosofia atual (...) é a de pôr a claro esse sistema de antes de todo sistema. Ele é o fundo de onde o nosso pensamento 'livre' emerge e sobre o qual cintila durante um instante. (Foucault, 1994 a, p.515)

Em As Palavras e as Coisas, Foucault detectou a existência de duas grandes descontinuidades na episteme da cultura ocidental, uma inaugurando a idade clássica, no limiar do século XVII, e outra inaugurando a idade moderna, no limiar do século XIX. A hipótese de Foucault é que os saberes clássicos constituem-se enquanto análise de uma ordem lógica de representações no sistema de signos da linguagem. Tal afirmação implica o reconhecimento de uma profunda mutação epistêmica em relação ao modo de ser da ordem que possibilitava os chamados saberes renascentistas. No limiar do século XVII a linguagem perde seu parentesco com as coisas, deixa de ser o locus da possível enunciação do seu ser oculto, deixa de falar das coisas enquanto tais, perde a sua dimensão de profundidade, que exigia o delicado trabalho de interpretação. Isto se dá porque, a partir do século XVII, a linguagem se torna instrumento, torna-se um espelho oco que apenas reflete com precisão aquilo que representa, perdendo qualquer contato com as próprias coisas e deixando de pretender enunciar o seu ser primordial. A palavra deixa de ser a palavra de Deus, deixa de trazer consigo a marca ou os sinais que permitiriam ler o texto do mundo criado para tornarse uma ferramenta da produção de novos conhecimentos: "A linguagem se retira do meio dos seres para entrar na sua era de transparência e neutralidade" (Foucault, 1995, p.71). A busca do conhecimento deixa de orientar-se pela busca de similitudes e semelhanças entre as palavras e as coisas e o conhecimento passa a duvidar da evidência fornecida pelos sentidos. Conhecer, portanto, não é mais buscar semelhanças entre as palavras e as coisas, mas é comparar racionalmente a matéria decompondo-a em termos de suas identidades e diferenças, segundo critérios de medida e de ordem.

Para Foucault, o saber clássico é um saber que mantém uma relação geral com a "'máthêsis' entendida como ciência universal da medida e da ordem", determinação essencial para o surgimento de saberes antes inexistentes (Foucault, 1995, p.71). Enquanto a filosofia trata da representação em geral, as outras ordens de saber da episteme clássica lidam com representações de tipo particular: por exemplo, sobre os seres vivos, sobre a medida das riquezas e sobre a linguagem como meio de representação. Na episteme clássica, a relação de representação entre o signo e o conteúdo representado deixa de ser avaliada tendo em vista as próprias coisas, pois é com- 
preendida agora como a relação entre "a idéia de uma coisa e a idéia de uma outra" (Foucault, 1995, p.79). As palavras, portanto, não constituem mais as marcas das próprias coisas, mas tornam-se signos, isto é, substitutos das coisas, seus representantes, e o que se vincula entre os signos são apenas idéias. Signo é uma idéia ou imagem que pode ser associada a uma outra idéia ou imagem, substituindo-a, pois possui em si própria um "poder representativo". Deste modo, há signo quando uma representação se liga a outra representação e representa em si mesma essa relação. Os signos não precisam ser interpretados, não guardam consigo qualquer opacidade de sentido, precisam apenas ser analisados em seu encadeamento no "quadro completo dos signos", o qual oferece a "imagem das coisas" (Foucault, 1995, p.81). As idéias-signo tornam-se, pois, uma "imagem do mundo" qualquer semelhança com as análises heideggerianas não terá sido casual - e isto basta ao cogito em sua apreensão de uma realidade fundada na ordem e na medida geométricas. Para Foucault, essa relação com a ordem tematizada pelo cartesianismo é essencial para a compreensão do surgimento de saberes antes inexistentes, como a História Natural, a Análise das Riquezas e a Gramática Geral, saberes da ordem no plano dos seres vivos, das necessidades e das palavras:

Projeto de uma ciência geral da ordem; teoria dos signos analisando a representação; disposição em quadros ordenados das identidades e das diferenças: assim se constituiu na idade clássica um espaço de empiricidade que não existira até o fim do Renascimento e que estava condenado a desaparecer desde o início do século XIX. (...) O que torna possível o conjunto da episteme clássica é, primeiramente, a relação a um conhecimento da ordem. (Foucault, 1995, p.87)

Por sua vez, o surgimento das ciências propriamente empíricas, na virada para o século XIX, tais como Biologia, Economia e Filologia, tem de ser compreendido não como um aperfeiçoamento progressivo das antigas formas de conhecimento, mas em termos de uma descontinuidade no plano epistêmico. A arqueologia não visa explicar a causa primeira das descontinuidades entre as epistemes, mas demonstrar como as configurações próprias a cada saber em sua positividade se modificaram e como se formou um novo solo comum entre as novas positividades: "Filologia, biologia e economia política se constituem não no lugar da Gramática Geral, da História Natural e da Análise das Riquezas, mas lá onde esses saberes não existiam, no espaço em que deixavam em branco..." (Foucault, 1995, pp.221-2). A tese geral é que se teria rompido a antiga coerência vigente entre a teoria da representação e as análises da linguagem, das ordens naturais, da riqueza e do valor tal como efetuadas entre os séculos XVII e XVIII, de sorte que o nascimento das ciências propriamente empíricas, no 
limiar do século XIX, deveu-se a uma mutação no âmbito profundo dos modos de ser da ordem, a qual atingiu o coração da episteme clássica, a teoria da representação, que "desaparece como fundamento geral de todas as ordens possíveis" até então (Foucault, 1995, p.13). Em outras palavras, o fim do pensamento clássico coincide com a liberação da linguagem, do ser vivo e da necessidade do âmbito da representação.

Com o surgimento da episteme moderna, a História substitui a Ordem e se afirma como o a priori (histórico) que permite o nascimento das novas empricidades, instância a partir da qual podem surgir os objetos empíricos. Em outras palavras, a história, pensada como espaço epistêmico, torna-se "a base a partir da qual todos os seres ganham existência e chegam à sua cintilação precária. Modo de ser de tudo o que nos é dado na experiência, a História tornou-se assim o incontornável de nosso pensamento" (Foucault, 1995, p.233). Essa mutação epistêmica afetou a antiga autonomia soberana da representação e da análise das representações enquanto constituintes do solo comum do saber clássico, pois as novas noções empíricas de vida, linguagem e trabalho escapam ao livre jogo das representações para aparecer, pela primeira vez, em sua concretude objetiva, isto é, como objetos empíricos. Vida, trabalho e linguagem perdem seu estatuto de transparência transpassada por representações para tornarem-se entidades obscuras, dotadas de uma interioridade regida por leis próprias, que agora cumpre conhecer por meio de outros métodos. Agora, será preciso arrancar a verdade da espessura das próprias coisas no interior da história: forma-se assim um novo regime de saberes que incorpora a historicidade, a finitude e o condicionamento empírico dos seus objetos.

A partir de agora, pensa Foucault, é possível que o próprio sujeito do conhecimento se transforme em figura de carne e osso, e este é justamente o momento em que o "homem aparece com sua posição ambígua de objeto para um saber e de sujeito que conhece: soberano submisso, espectador olhado" (Foucault, 1995, p.238). Finalmente, o homem faz sua entrada na cena do conhecimento, ao tornar-se, ele próprio, sujeito e objeto empírico. $\mathrm{O}$ 'Eu penso' deixa agora de estar imediata e necessariamente conectado ao 'Eu existo', e, de qualquer modo, não é mais o pensamento que me revela como existente, mas sim entidades objetivas que preexistem à minha existência: vida, trabalho e linguagem. A partir de agora, portanto, o cogito não pode mais ser simplesmente assumido como a instância segura e indubitável das representações, mas tem de ser interrogado em seu verdadeiro modo (histórico) de ser. A figura do Homem, que a partir de então ocupará o centro de interesse das Ciências Humanas, surge dos interstícios entre as novas ciências empíricas - como Biologia, Filologia e Economia Política, que o tematizam como o ser que vive, fala e trabalha - e da filosofia kantiana, que o interroga numa analítica do sujeito transcendental. Para Foucault, 
apenas então o Homem surge como o sujeito que se tematiza, como o ser que delimita uma região de conhecimento a respeito de si mesmo. Em suma, o Homem finito (que vive, fala e trabalha) torna-se o fundamento de todo saber finito sobre si mesmo, isto é, de todo saber sobre as positividades empíricas que o determinam. Conhecer não é mais ordenar representações, mas conhecer o Homem e esclarecer as possibilidades do conhecimento "a partir dos conteúdos empíricos que nele são dados" (Foucault, 1995, p.334). O Homem é, pois, o local onde se entrecruzam o desconhecido e o impensado, o conhecido e o pensamento; paradoxalmente, o Homem surge para o pensamento moderno como um ser perpassado por domínios que ele não pode compreender, e, entretanto, como ser dotado de uma inteligibilidade capaz de aumentar sempre gradativamente o espaço do que se pode esclarecer. Por isso, o cogito moderno não é mais fundamento, mas uma tarefa contínua e incessamentemente retomada. A conclusão a que chega Foucault é conhecida: o homem não é o mais velho tema de questionamento dos saberes ocidentais, mas apenas uma "brecha na ordem das coisas", uma configuração das novas formas de conhecimento que propiciou o surgimento de "todas as quimeras dos novos humanismos" e "todas as facilidades de uma 'antropologia' entendida como reflexão geral, meio positiva, meio filosófica, sobre o homem" (Foucault, 1995, p.13).

Por certo, há diferenças inegáveis entre as interpretações que Heidegger e Foucault oferecem a respeito da gênese da modernidade, visto que Foucault, à diferença de Heidegger, não enfatiza o cogito cartesiano como o suporte certo e seguro de todas as representações claras e distintas, isto é, como a instância que faz com que cada representação se constitua como representação objetiva para um sujeito. Ou seja, Foucault se atém a uma consideração da autonomia dos signos lingüísticos em sua articulação metódica como condição do conhecimento certo e seguro. Com isso, perde-se de vista a mutação ontológica observada por Heidegger, em vista da qual, já no século XVII, o modo de ser do homem se transformara no subjectum que subjaz e unifica as representações de conhecimento, o que, evidentemente, não implicava confundir o cogito cartesiano com o posterior surgimento do homem de carne e osso. Ao proceder desta maneira, Foucault deixa de observar o elo de continuidade que se instaura entre o subjetivismo cartesiano e a posterior antropologia do século 19, como o fizera Heidegger. Por sua vez, Foucault enxerga a gênese da modernidade no momento mesmo em que se tornou possível um espaço antropológico de tematização do homem como sujeito e objeto do conhecimento, isto é, no instante de instauração da episteme Moderna, na virada para o século XIX. Dreyfus e Rabinow, em seu comentário à análise foucaultiana do quadro de Velásquez, As meninas, enfatizam exatamente que, naquele quadro, segundo Foucault, "O que é representado são as funções da representação. O que não é 
representado é um sujeito unificado e unificador que faz estas representações, tornando-as objetos. Na opinião de Foucault, este sujeito emergirá com o surgimento do homem de Kant" (Dreyfus; Rabinow, 1995, p, 27). No entanto, penso que tais diferenças não chegam a impor uma contraposição irreconciliável entre as conclusões a que ambos chegaram a respeito da modernidade. De maneira um tanto semelhante a Heidegger, também para Foucault trata-se de começar a pensar sem incorrer no dogmatismo antropológico, para o quê é preciso desenraizar o pensamento moderno de suas pretensões humanistas. Para ambos, o humanismo foi a base de justificação de males políticos, tanto de esquerda quanto de direita, visto que, como observou Foucault, também a própria tecnocracia é essencialmente humanista, na medida em que o tecnocrata - como o revolucionário de esquerda - é aquele que justifica suas ações e seus saberes em nome da felicidade do Homem: "Nossa tarefa é nos desvencilhar definitivamente do humanismo e é nesse sentido que nosso trabalho é político, na medida em que todos os regimes do leste e do oeste fazem passar sua má mercadoria pelo pavilhão do humanismo" (Foucault, 1994a, p.516).

A fim de prosseguir no trabalho de aproximação entre os diagnósticos da modernidade de Foucault e de Heidegger, importa ainda assinalar a coerência interna da obra de Foucault em sua passagem da fase arqueológica para a fase genealógica, sobretudo no que respeita ao seu momento final, marcado pela análise da biopolítica. Afinal, a passagem do século XVIII para o XIX, momento em que se constituíram as figuras do homem e da vida como objetos empíricos é, também, o momento em que surgiram os procedimentos de uma política estatal que visava disciplinar o corpo das populações e gerir a vida do homem como ser vivo, inaugurando-se a biopolítica. A partir de então, a antiga anátomo-política das relações de poder-saber, implementadas pelos dispositivos disciplinares que, ao longo dos séculos XVII e XVIII, constituíram o corpo e a individualidade do súdito do antigo regime, o sujeito assujeitado, faz-se acompanhar pelo fato novo de uma "assunção da vida pelo poder", isto é, de uma "tomada de poder sobre o homem vivo, uma espécie de estatização do biológico" (Foucault, 2000, pp.285-286). Como se sabe, o que está em jogo no empreendimento genealógico de Foucault, a partir dos anos setenta, é um questionamento acerca do poder, uma análise dos seus mecanismos, efeitos, relações e dispositivos, por meio dos quais se ativam diferentes formas de dominação em âmbitos variados da vida institucional. Contrariamente às concepções jurídico-política e econômica do poder, segundo as quais o poder seria um bem que uns possuem em detrimento dos outros, Foucault inovou a teoria social ao pensar o poder como um conjunto plural de práticas e relações sociais constituídas historicamente, ativas por meio de dispositivos estratégicos que alcançam a todos, visto que tais poderes se exercem no interior das ins- 
tituições sociais em que se desenrola a vida cotidiana do indivíduo moderno: a escola, a fábrica, a prisão, a família, o hospital, o exército. Nesse contexto micro-político, o poder é pensado como relação que se exerce, que impõe efeitos, que funciona de maneira positiva ao produzir realidades e não apenas como força negativa de destruição e repressão. Por isso mesmo, qualquer reação ou resistência contra uma relação de poder se dá somente a partir de dentro das redes de poder, num embate de forças. Em suma, na primeira etapa de sua pesquisa genealógica Foucault desloca a centralidade tradicional do questionamento jurídico-político do direito, focado na questão da soberania e da obediência ao poder constituído, em vista de uma análise do poder centrada no problema da dominação e da sujeição, isto é, da produção dos súditos, dos sujeitos assujeitados: "a fabricação dos sujeitos muito mais do que a gênese do soberano: aí está o tema geral" (Foucault, 2000, p.52).

Segundo a concepção genealógica do poder, os grandes aparelhos de poder, como o Estado, somente funcionam sobre a base autônoma de uma micro-política das relações de dominação. Esta nova mecânica do poder surge lentamente, a partir do século XVII, e se exerce por meio da disciplina e da constante vigilância, de maneira a extrair dos corpos individuais mais tempo e trabalho, mais utilidade e docilidade, dispensando-se, assim, a presença efetiva do soberano. Em síntese, Foucault demonstra que a disciplina é uma forma de organização do espaço e de disposição dos homens no espaço, visando otimizar sua atividade, bem como é uma forma de organização, divisão e controle do tempo em que as atividades humanas são desenvolvidas, com o objetivo de produzir rapidez e precisão de movimentos. A estes elementos se acrescentam ainda a vigilância e o exame, considerados como elementos essenciais do novo poder disciplinar. Foi assim que Foucault descobriu um corpo individual produzido pelo investimento produtivo de uma complexa rede de micro-poderes disciplinares, que atuavam de maneira a tornar possível a utilização dos corpos em nome da exploração otimizada de suas capacidades e potencialidades.

Foi no curso dessa investigação genealógica a respeito da nova dinâmica de exercício dos micro-poderes disciplinares que Foucault chegou à formulação dos conceitos de biopoder e biopolítica, tendo em vista explicar o aparecimento, na virada para o século XIX, de um poder disciplinador e normalizador que já não se exercia sobre os corpos individualizados, nem se encontrava disseminado no tecido institucional da sociedade, mas se concentrava na figura do Estado e se exercia a título de política estatal com pretensões de administrar a vida e o corpo da população. Foucault observará, então, o aparecimento de uma nova tecnologia de poder que já não é mais estritamente da ordem do disciplinar, e que, sem excluí-lo, vai se acrescentar a ele e transformá-lo parcialmente, agindo em outro nível e escala, por 
meio de mecanismos e instrumentos distintos daqueles por meio dos quais o poder disciplinar continuava a se exercer. Essa nova tecnologia de poder se aplica não mais ao "homem-corpo", mas ao "homem vivo", isto é, ao homem enquanto espécie ou enquanto população, entidade sujeita a processos vitais como o nascimento, a morte, a proliferação das doenças, a longevidade, a fecundidade etc., os quais tornam-se objeto de mensuração e regulação, visando o "equilíbrio global" em relação aos seus "perigos internos". O surgimento da biopolítica é concomitante às primeiras demografias, assim como também à introdução da medicina como higiene pública visando a medicalização dos fenômenos de população, que se tornam de uma só vez um problema político e científico. O que se produz por meio da atuação específica do biopoder não é mais apenas o indivíduo dócil e útil, mas é a própria gestão produtiva da vida do corpo social. Se antes o poder soberano exercia seu direito sobre a vida na medida em que podia matar, a partir do século XIX se opera uma transformação decisiva, que dá lugar ao biopoder como nova modalidade de exercício do poder soberano, que agora será um "poder de causar a vida ou devolver à morte" (Foucault, 1999, p.130).

Ali onde nossa consciência moderna nos levaria a louvar o caráter humanitário de intervenções políticas que visam incentivar, proteger, estimular e administrar o regime vital da população, ali também Foucault descobre a contrapartida sangrenta desta obsessão do novo poder estatal com o cuidado purificador da vida. Em outras palavras, Foucault compreendeu que a partir do momento em que a vida passou a se constituir no elemento político por excelência, o qual tem de ser administrado, calculado, gerido, regrado e normalizado, o que se observa não é um decréscimo da violência, muito pelo contrário, pois tal cuidado da vida traz consigo, de maneira necessária, a exigência contínua e crescente da morte em massa, visto que é apenas no contraponto da violência depuradora que se podem garantir mais e melhores meios de sobrevivência a uma dada população. Não há, portanto, contradição entre biopolítica e tanatopolítica, isto é, entre o poder de gerência e incremento da vida e o poder de matar aos milhões para garantir as melhores condições vitais possíveis. A descoberta da importância política do racismo como forma privilegiada de atuação estatal, fartamente empregada ao longo do surto imperialista europeu do século XIX, e radicalizada cotidianamente ao longo do século XX, tendo no nazismo e no stalinismo seu ápi$\mathrm{ce}$, tem de ser compreendida segundo os termos daquela mutação operada na própria natureza do exercício do poder soberano. Para Foucault, num contexto histórico biopolítico não há Estado que não se valha de formas amplas e variadas de racismo como justificativa para exercer seu direito de matar em nome da preservação, da intensificação e da purificação da vida.

Ora, qual é a relação entre tais análises foucaultianas e as considerações de Heidegger a respeito da modernidade tecnológica? Penso que as 
análises foucaultianas a respeito da modernidade como época do biopoder constituem uma confirmação histórica da tese ontológico-historial de Heidegger segundo a qual, na modernidade, o poder se tornou o elemento constitutivo de todas as relações entre o homem e a natureza e entre os próprios homens, sob o impulso da vontade de poder que alimenta e põe em movimento o projeto metafísico do desvelamento tecnológico do ente na totalidade. Tanto Foucault quanto Heidegger analisam a constituição da modernidade como época determinada pelo humanismo metafísico que projeta no ente humano o estatuto de fundamento fundado, isto é, que faz do homem sujeito e objeto do conhecimento científico, mutação decisiva da modernidade, operacionalizada pela multiplicação das micro-tecnologias de assujeitamento do homem e da natureza, as quais culminam na biopolítica contemporânea. Por outro lado, as análises ontológico-historiais de Heidegger parecem elucidar o fundamento metafísico das análises foucaultianas do biopoder, fenômeno histórico que também se deixa esclarecer sob a ótica da compreensão da modernidade como época regida pela vontade de poder da subjetividade antropológica. Se, como afirma Foucault, a biopolítica é a política de nosso tempo, de uma época que politizou o fenômeno da vida por meio de sua gestão técnico-administrativa, então a técnica moderna - que para Heidegger transforma o homem em sujeito e objeto da maquinação tecnológica, isto é, em "fundo de reserva" - constitui a instância ontológica que possibilita que a vida humana seja simultaneamente produzida e aniquilada por meios técnico-científicos. O que se pretendeu argumentar neste texto, portanto, é que tanto a técnica moderna quanto a biopolítica constituem fenômenos complementares e auto-referentes, os quais encontram seu fundamento comum no humanismo antropológico que, não por acaso, esteve no centro das críticas de Heidegger e Foucault à modernidade, a despeito das diferenças que especificam tais diagnósticos.

DUARTE, A. Heidegger and Foucault, critics of modernity: humanism, technics and biopolitics. Trans/Form/Ação, (São Paulo), v.29(2), 2006, p.95-114.

- ABSTRACT: I intend to discuss Foucault's and Heidegger's critical diagnosis of Modernity emphasizing its continuities. Generally speaking, it is possible to argue that in Heidegger philosophical reflection assumes itself as essentially historical, while in Foucault's case historical investigation assumes itself as an essentially philosophical task. Although recognizing the differences between Foucault's and Heidegger's general theoretical approaches, I argue that both consider that, in order to understand who we are today, it is necessary to elaborate a critical understanding of Modernity. In both cases, Modernity is viewed as a historical epoch characterized by humanism, i.e., by the projection of human 
beings as 'master' of all beings (Heidegger) and as subject and object of powerknowledge relationships (Foucault). This epocal mutation in the way man is conceived was decisive in order to liberate the modern scientific revolution that later culminated in modern technology and in biopolitics. If, as Foucault says, biopolitics is the politics of our time, i.e., of an epoch that has politicized life by means of the calculated administration of all phenomena of life-population, then modern technique, which implies the conception of man as the subjected-subject of technology, constitutes the instance by which human life can be protected, promoted, generated, as well as destroyed and discarded.

- KEYWORDS: Foucault; Heidegger; Modernity; humanism; modern technology; biopolitics.

\section{Referências bibliográficas}

DREYFUS, H., RABINOW, P.Michel Foucault. Uma trajetória filosófica. Rio de Janeiro: Forense Universitária, 1995.

DONNELLY, M. "Sobre los diversos usos de la noción de biopoder". In Michel Foucault, Filósofo. Barcelona: Gedisa, 1999, pp.193-197.

FOUCAULT, M. Dits et Écrits, I. Paris: Gallimard, 1994a.

As palavras e as coisas. São Paulo: Martins Fontes, 1995.

Dits et Écrits, IV. Paris: Gallimard, 1994b.

Em defesa da sociedade. São Paulo: Martins Fontes, 2000

História da Sexualidade II - O uso dos prazeres. Rio de Janeiro, Graal, 1984a. 1999

História da sexualidade. Vol. 1 "A vontade de saber". Rio de Janeiro: Graal,

Vigiar e Punir. Rio de Janeiro: Vozes, $3^{\mathrm{a}}$ ed. , 1984b.

Microfísica do Poder. Rio de Janeiro: Graal, $3^{\mathrm{a}}$ ed., 1982.

HABERMAS, J. "Work and Weltanschaaung: the Heidegger controversy from a German perspective". In Critical Inquiry, n. 15, inverno de 1989.

HEIDEGGER, M. Holzwege. Frankfurt, Vittorio Klostermann, 1994a.

Einführung in der Metaphysik. Tübingen: Max Niemeyer, 1998.

Vorträge und Aufsätze. Stuttgart: Verlag Günther Neske, 1994b

MARTINS, C.J. "Michel Foucault: filosofia como diagnóstico do presente". In Cadernos da F.F.C. Marília: Unesp-Publicações, vol. 9, n.1, 2000, pp.149-167.

RABINOW, P."Modern and Countermodern: ethos and epoch in Heidegger and Foucault". In Gutting, G. (org.) The Cambridge Companion to Michel Foucault. Cambridge: Cambridge University Press, 1994, pp.197-214. 